\title{
cmaJOPEN
}

\section{Death after emergency department visits for opioid overdose in British Columbia: a retrospective cohort analysis}

\author{
Jessica Moe MD MSc, Mei Chong MSc, Bin Zhao MSc, Frank X. Scheuermeyer MD MHSc, \\ Roy Purssell MD, Amanda Slaunwhite PhD
}

Abstract

Background: Visits to the emergency department are critical opportunities to engage individuals after an overdose. We sought to estimate and compare the 12-month mortality between persons with visits to the emergency department related to opioid overdose and those with non-overdose-related visits.

Methods: We conducted a retrospective cohort study using the Provincial Overdose Cohort, which contains data for patients in British Columbia who had an opioid-related overdose between 2015 and 2017, along with a 20\% random sample of BC residents for comparison. We examined all nonfatal visits to the emergency department between Jan. 1, 2015, and Dec. 31, 2016, among persons aged 14 to 74 years and compared the 12-month mortality between those with overdose-related visits and those with non-overdoserelated visits. We estimated the hazard ratio for death, with adjustment for age, sex, comorbidity and disposition (discharged or left against medical advice).

Results: We included 3593 persons with overdose-related visits and 216453 with non-overdose-related visits to the emergency department. Those with overdose-related visits were younger, were predominantly male and had more mental health conditions. The 12-month crude mortality probability was $5.4 \%$ (95\% confidence interval [Cl] $4.7 \%-6.2 \%)$ in this group and $1.7 \%(95 \% \mathrm{Cl}$ $1.6 \%-1.8 \%)$ among those with non-overdose-related visits. After adjustment, for persons who were discharged, the 12-month mortality hazard was $3.5(95 \% \mathrm{Cl} 3.0-4.2)$ times higher among those with overdose-related visits than those with non-overdose-related visits. For persons who left against medical advice, the mortality hazard was $7.1(95 \% \mathrm{Cl} 4.0-12.5)$ times higher among those with opioid overdose.

Interpretation: Among persons with overdose-related visits to the emergency department, 12-month mortality was higher than among those with non-overdose-related visits. Overdose-related visits should prompt urgent evidence-based interventions (e.g., take-home naloxone kits, buprenorphine-naloxone induction) to prevent future deaths.

T he opioid overdose epidemic in North America has slowed the increase in Canadian life expectancy and contributed to a decline in life expectancy in British Columbia. ${ }^{1-3}$ More than 4 years since $\mathrm{BC}$ declared a public health emergency in April 2016, in response to rapidly rising overdose deaths ${ }^{4}$ the province continues to struggle to contain this epidemic. Tragically, overdose deaths have risen to unprecedented highs since the onset of the coronavirus disease 2019 (COVID-19) pandemic. In October 2020, overdose claimed 5.2 lives per day in BC, highlighting the urgency of the need to strengthen a multifaceted response and thereby to identify people at risk and prevent fatal outcomes. ${ }^{5}$

Visits to the emergency department are critical points of contact with persons at risk of overdose and death. From 2013 to 2017, emergency department visits for opioid misuse increased by $165 \%$ in Alberta and 144\% in Ontario. ${ }^{6,7}$ Furthermore, public health analyses indicate that $54 \%$ of persons with an overdose had visited an emergency department in the previous year, and $19 \%$ of those left against medical advice, indicating missed opportunities to intervene. ${ }^{8,9}$
For patients who present to the emergency department after an opioid overdose, health care providers have an opportunity to offer potentially life-saving treatments, such as take-home naloxone kits and induction of buprenorphine-naloxone. ${ }^{10,11}$ One seminal study showed that initiation of buprenorphinenaloxone in the emergency department more than doubled 30 -day retention in addictions care relative to referral alone. ${ }^{12}$

To optimize and optimally target emergency department interventions toward specific subgroups at highest risk of future fatal events, we must understand individuals' outcomes after overdose-related emergency department visits and predictors of risk. Therefore, our primary objective was to estimate and

\section{Competing interests: None declared.}

This article has been peer reviewed.

Correspondence to: Jessica Moe, jessica.moe@ubc.ca

CMAJ Open 2021. DOI:10.9778/cmajo.20200169 
compare the 12-month mortality between persons with visits to the emergency department related to opioid overdose and persons with visits not related to overdose. The secondary objective was to estimate 12 -month mortality among persons with overdose-related visits, according to visit disposition: admission, discharge with approval or leaving against medical advice.

\section{Methods}

\section{Study design and data sources}

In this retrospective cohort study, we used the BC Provincial Overdose Cohort, a collection of linked administrative data for persons who experienced an opioid-related overdose between Jan. 1, 2015, and Dec. 31, 2017. This database also includes a $20 \%$ random sample of the BC population who did not experience an opioid-related overdose as a reference. Under the declaration of a public health emergency that resulted from rising overdose deaths, the provincial health officer issued public health orders for acquisition of these data. This enabled the BC Centre for Disease Control to lead creation of the cohort, in collaboration with regional health authorities, the Ministry of Health, BC Emergency Health Services and the BC Coroners Service. The Provincial Overdose Cohort is refreshed annually to include new persons who have had an overdose and to update information on those already in the database. ${ }^{13-15}$

The Provincial Overdose Cohort captures opioid-related overdose events using specific case definitions in multiple data sources: BC Emergency Health Services; BC Drug and Poison Information Centre; case reporting by emergency physicians; the National Ambulatory Care Reporting System (NACRS), the Discharge Abstract Database (both maintained by the Canadian Institute for Health Information) and the BC Medical Services Plan database; and overdose-related deaths recorded by the BC Coroners Service or the Vital Statistics Agency. An additional 5 years of records (from Jan. 1, 2010, to Dec. 31, 2014) of health care utilization (NACRS, Discharge Abstract Database, BC Medical Services Plan), prescription dispensations (PharmaNet) and incarceration (admission and release dates for provincial correctional institutions) are appended for every person in the Provincial Overdose Cohort.

The provincial Client Roster database provides basic demographic information such as sex, birthdate, death date (if applicable) and residence geography as of Dec. 31 each year. Data are linked using deterministic and probabilistic algorithms incorporating name, birthdate, sex and provincial health number. ${ }^{14,16}$ Greater detail on case definitions and methodology for the Provincial Overdose Cohort are available elsewhere. ${ }^{9,10}$

We examined administrative data for emergency department visits from linked NACRS data in the Provincial Overdose Cohort. The NACRS captures information on emergency visits in Canada; for 2015/16, it included data from 29 contributing emergency departments in BC..$^{17-19}$ Visit acuity was defined in the NACRS using the Canadian Triage and Acuity Scale (ctas-phctas.ca), a national tool that allows care providers in emergency departments to prioritize care.

\section{Study population and definitions}

Our study population consisted of a study cohort and a comparison cohort. The study cohort comprised persons 14 to 74 years of age who made at least 1 nonfatal overdose-related visit to the emergency department between Jan. 1, 2015, and Dec. 31, 2016. We defined nonfatal visits as those with a disposition other than death. Consistent with previous literature, ${ }^{20,21}$ we restricted our sample to this age span to capture the most common demographic of adolescents and adults experiencing overdose in BC..$^{22}$ We excluded older persons ( $\geq 75 \mathrm{yr}$ ), who would be expected to have higher natural comorbidity and mortality.

We extracted data for all nonfatal overdose-related visits to the emergency department based on the International Statistical Classification of Diseases and Related Health Problems, 10th Revision, diagnostic codes T40.1 (poisoning due to heroin) and T40.6 (poisoning due to other/unspecified opioids), a previously described approach to identify illicit opioid overdoses. ${ }^{14}$ We defined the first nonfatal overdose-related visit made by each person as the index overdose visit.

Persons in the Provincial Overdose Cohort who had only non-overdose-related emergency department visits, with the same age restrictions and time frame as described above, constituted our comparison cohort. We defined the first nonfatal, non-overdose-related visit as the index non-overdose visit.

All participants had to be present in the Client Roster database for 3 consecutive years (the index visit year, as well as 1 year before and 1 year after) to ensure the validity of our assumption that 1 year of health utilization history and mortality during the 1-year follow-up period were captured.

\section{Outcomes}

Our primary outcome was all-cause mortality within 12 months after the index overdose-related or non-overdoserelated emergency department visit. Secondary outcomes were all-cause mortality at 1, 3 and 6 months after the index overdose-related or non-overdose-related emergency department visit. We extracted death dates from the following data sources: the BC Coroners Service, the Vital Statistics Agency or the provincial Client Roster.

\section{Statistical analysis}

We conducted descriptive analyses of individual and visit characteristics at the time of the index emergency department visit using proportions for categorical variables and medians with interquartile ranges for continuous variables.

We used Kaplan-Meier product-limit estimates to summarize the crude proportion of mortality among persons who had overdose-related and non-overdose-related visits. We reported crude mortality proportions at 1, 3, 6 and 12 months from the index visit, stratified by disposition status: discharged with approval, left against medical advice or admitted to hospital. We plotted Kaplan-Meier curves to illustrate the progress of mortality within 12 months from the index visit, stratified by disposition status.

We used multivariable Cox regression to estimate and compare the hazard of death 12 months after the index 
Table 1 (part 1 of 2): Characteristics associated with overdose-related and non-overdose-related visits to emergency departments in British Columbia, 2015-2016

Patient group and reason for visit; no. (\%) of patients*

\begin{tabular}{|c|c|c|c|c|c|c|}
\hline \multirow[b]{3}{*}{ Characteristic } & \multicolumn{6}{|c|}{ Patient group and reason for visit; no. (\%) of patients* } \\
\hline & \multicolumn{2}{|c|}{ All patients } & \multicolumn{2}{|c|}{ Discharged } & \multicolumn{2}{|c|}{ Left against medical advice } \\
\hline & $\begin{array}{l}\text { Overdose } \\
n=3593\end{array}$ & $\begin{array}{c}\text { Non-overdose } \\
n=216453\end{array}$ & $\begin{array}{l}\text { Overdose } \\
n=3133\end{array}$ & $\begin{array}{c}\text { Non-overdose } \\
n=187932\end{array}$ & $\begin{array}{l}\text { Overdose } \\
n=150\end{array}$ & $\begin{array}{c}\text { Non-overdose } \\
n=7960\end{array}$ \\
\hline \multicolumn{7}{|l|}{ Index visits to ED } \\
\hline \multicolumn{7}{|l|}{ Health authority } \\
\hline Interior Health & $73(2.0)$ & $23432(10.8)$ & $66(2.1)$ & $20028(10.7)$ & $2(1.3)$ & $765(9.6)$ \\
\hline Fraser Health & $1900(52.9)$ & $93487(43.2)$ & $1652(52.7)$ & $81882(43.6)$ & $42(28.0)$ & $3694(46.4)$ \\
\hline $\begin{array}{l}\text { Vancouver Coastal } \\
\text { Health }\end{array}$ & $1407(39.2)$ & $51274(23.7)$ & $1234(39.4)$ & $44539(23.7)$ & $96(64.0)$ & $1903(23.9)$ \\
\hline Island Health & $67(1.9)$ & $38952(18.0)$ & $60(1.9)$ & $33638(17.9)$ & $1(0.7)$ & $1200(15.1)$ \\
\hline Northern Health & $137(3.8)$ & $8578(4.0)$ & $113(3.6)$ & $7208(3.8)$ & $8(5.3)$ & $371(4.7)$ \\
\hline Unknown & $9(0.3)$ & $730(0.3)$ & $8(0.3)$ & $637(0.3)$ & $1(0.7)$ & $27(0.3)$ \\
\hline Arrival by ambulance & $2966(82.5)$ & $33062(15.3)$ & $2585(82.5)$ & 23525 (12.5) & $139(92.7)$ & $1261(15.8)$ \\
\hline \multicolumn{7}{|c|}{ Canadian Triage and Acuity Scale } \\
\hline 1 (resuscitation) & $128(3.6)$ & $1429(0.7)$ & $73(2.3)$ & $425(0.2)$ & $5(3.3)$ & $7(0.1)$ \\
\hline 2 (emergent) & $1096(30.5)$ & $31827(14.7)$ & $888(28.3)$ & 23023 (12.3) & $35(23.3)$ & $426(5.4)$ \\
\hline 3 (urgent) & $2147(59.8)$ & $100094(46.2)$ & $1968(62.8)$ & $86752(46.2)$ & $103(68.7)$ & $3393(42.6)$ \\
\hline 4 (less urgent) & $189(5.3)$ & $73596(34.0)$ & $174(5.6)$ & $69851(37.2)$ & $6(4.0)$ & $2679(33.7)$ \\
\hline 5 (nonurgent) & $19(0.5)$ & $5415(2.5)$ & $19(0.6)$ & $4997(2.7)$ & $0(0.0)$ & $353(4.4)$ \\
\hline Unknown & $14(0.4)$ & $4092(1.9)$ & $11(0.4)$ & $2884(1.5)$ & $1(0.7)$ & $1102(13.8)$ \\
\hline $\begin{array}{l}\text { Visit length of stay, h, } \\
\text { median (IQR) }\end{array}$ & $3.5(2.2-5.9)$ & $2.8(1.7-4.5)$ & $3.5(2.2-5.8)$ & $2.8(1.7-4.3)$ & $3.5(2.2-5.8)$ & $2.8(1.7-4.3)$ \\
\hline \multicolumn{7}{|l|}{ Disposition after index visit } \\
\hline Discharged & $3133(87.2)$ & $187932(86.8)$ & - & - & - & - \\
\hline $\begin{array}{l}\text { Left against medical } \\
\text { advice }\end{array}$ & $150(4.2)$ & $7960(3.7)$ & - & - & - & - \\
\hline Admitted or transferred & $310(8.6)$ & $20561(9.5)$ & - & - & - & - \\
\hline \multicolumn{7}{|l|}{ Patients } \\
\hline Sex, female & $1098(30.6)$ & $108524(50.1)$ & $939(30.0)$ & 95837 (51.0) & $33(22.0)$ & $3724(46.8)$ \\
\hline Age, yr, median (IQR) & $35.0(27.0-46.0)$ & $41.0(28.0-56.0)$ & $35.0(27.0-46.0)$ & $42.0(28.0-56.0)$ & $35.0(27.0-46.0)$ & $42.0(28.0-56.0)$ \\
\hline \multicolumn{7}{|l|}{ Age group, yr } \\
\hline $14-35$ & $1836(51.1)$ & $83451(38.6)$ & $1618(51.6)$ & $75016(39.9)$ & $74(49.3)$ & 3815 (47.9) \\
\hline $36-55$ & $1458(40.6)$ & $72846(33.7)$ & $1268(40.5)$ & $64063(34.1)$ & $63(42.0)$ & $2732(34.3)$ \\
\hline $56-74$ & $299(8.3)$ & $60156(27.8)$ & 247 (7.9) & $48853(26.0)$ & $13(8.7)$ & $1413(17.8)$ \\
\hline \multicolumn{7}{|c|}{ Material deprivation quintile† } \\
\hline 1 (most deprived) & $391(16.6)$ & $37873(19.6)$ & $331(16.3)$ & $33318(19.7)$ & $21(25.6)$ & $1297(18.7)$ \\
\hline 2 & 289 (12.3) & $37265(19.3)$ & $238(11.7)$ & $32714(19.4)$ & $11(13.4)$ & $1263(18.3)$ \\
\hline 3 & $347(14.7)$ & $36920(19.1)$ & $301(14.8)$ & $32212(19.1)$ & $12(14.6)$ & 1265 (18.3) \\
\hline 4 & $445(18.9)$ & 38403 (19.9) & $392(19.3)$ & $33381(19.8)$ & $12(14.6)$ & $1375(19.9)$ \\
\hline 5 (least deprived) & $883(37.5)$ & $42981(22.2)$ & $771(37.9)$ & $37144(22.0)$ & $26(31.7)$ & $1719(24.8)$ \\
\hline \multicolumn{7}{|c|}{ Elixhauser index with mental health } \\
\hline 0 & $2606(72.5)$ & $197785(91.4)$ & $2379(75.9)$ & $179940(95.7)$ & $128(85.3)$ & $7586(95.3)$ \\
\hline 1 & $451(12.6)$ & $10313(4.8)$ & $339(10.8)$ & $4920(2.6)$ & $10(6.7)$ & $234(2.9)$ \\
\hline$\geq 2$ & $536(14.9)$ & $8355(3.9)$ & $415(13.2)$ & $3072(1.6)$ & $12(8.0)$ & $140(1.8)$ \\
\hline
\end{tabular}


Table 1 (part 2 of 2): Characteristics associated with overdose-related and non-overdose-related visits to emergency departments in British Columbia, 2015-2016

\begin{tabular}{|c|c|c|c|c|c|c|}
\hline \multirow[b]{3}{*}{ Characteristic } & \multicolumn{6}{|c|}{ Patient group and reason for visit; no. (\%) of patients* } \\
\hline & \multicolumn{2}{|c|}{ All patients } & \multicolumn{2}{|c|}{ Discharged } & \multicolumn{2}{|c|}{ Left against medical advice } \\
\hline & $\begin{array}{l}\text { Overdose } \\
n=3593\end{array}$ & $\begin{array}{c}\text { Non-overdose } \\
n=216453\end{array}$ & $\begin{array}{l}\text { Overdose } \\
n=3133\end{array}$ & $\begin{array}{c}\text { Non-overdose } \\
n=187932\end{array}$ & $\begin{array}{l}\text { Overdose } \\
n=150\end{array}$ & $\begin{array}{c}\text { Non-overdose } \\
n=7960\end{array}$ \\
\hline \multicolumn{7}{|c|}{ Elixhauser index without mental health } \\
\hline 0 & $3287(91.5)$ & 201901 (93.3) & 2909 (92.9) & $181496(96.6)$ & $144(96.0)$ & $7748(97.3)$ \\
\hline 1 & $187(5.2)$ & $8478(3.9)$ & $145(4.6)$ & $4251(2.3)$ & $2(1.3)$ & $145(1.8)$ \\
\hline$\geq 2$ & 119 (3.3) & $6074(2.8)$ & $79(2.5)$ & $2185(1.2)$ & $4(2.7)$ & $67(0.8)$ \\
\hline \multicolumn{7}{|l|}{ Psychiatric comorbidities } \\
\hline Anxiety & $561(15.6)$ & $11032(5.1)$ & $478(15.3)$ & $9035(4.8)$ & $10(6.7)$ & $501(6.3)$ \\
\hline Depression & $611(17.0)$ & $13113(6.1)$ & $499(15.9)$ & $10379(5.5)$ & $18(12.0)$ & $590(7.4)$ \\
\hline Schizophrenia & $364(10.1)$ & $2928(1.4)$ & $319(10.2)$ & $1658(0.9)$ & $12(8.0)$ & $135(1.7)$ \\
\hline Personality disorders & $195(5.4)$ & $992(0.5)$ & $161(5.1)$ & $582(0.3)$ & $3(2.0)$ & $45(0.6)$ \\
\hline \multicolumn{7}{|c|}{$\geq 1$ prescription medication in $365 \mathrm{~d}$ before index visit } \\
\hline Opioids for analgesia & $1232(34.3)$ & $47502(21.9)$ & $1048(33.5)$ & 40325 (21.5) & $54(36.0)$ & $1666(20.9)$ \\
\hline Opioid agonist therapy & $1375(38.3)$ & $3985(1.8)$ & $1215(38.8)$ & $2997(1.6)$ & $73(48.7)$ & $411(5.2)$ \\
\hline $\begin{array}{l}\text { Benzodiazepines and } \\
\text { z-drugs } \ddagger\end{array}$ & $1094(30.4)$ & $32867(15.2)$ & $934(29.8)$ & $26845(14.3)$ & $31(20.7)$ & $1280(16.1)$ \\
\hline $\begin{array}{l}\text { Antidepressant and } \\
\text { antipsychotic } \\
\text { medications }\end{array}$ & $1976(55.0)$ & $44193(20.4)$ & $1702(54.3)$ & $35988(19.1)$ & $74(49.3)$ & $1920(24.1)$ \\
\hline $\begin{array}{l}\text { Incarceration in } 365 \mathrm{~d} \\
\text { before index visit }\end{array}$ & $788(21.9)$ & $2422(1.1)$ & $708(22.6)$ & $1887(1.0)$ & $33(22.0)$ & $230(2.9)$ \\
\hline \multicolumn{7}{|c|}{ Health care encounters in $365 \mathrm{~d}$ before index visit, median (IQR) } \\
\hline Hospitalization & $0.0(0.0-1.0)$ & $0.0(0.0-0.0)$ & $0.0(0.0-1.0)$ & $0.0(0.0-0.0)$ & $0.0(0.0-1.0)$ & $0.0(0.0-0.0)$ \\
\hline Ambulance & $1.0(0.0-1.0)$ & $0.0(0.0-0.0)$ & $1.0(0.0-1.0)$ & $0.0(0.0-0.0)$ & $1.0(0.0-1.0)$ & $0.0(0.0-0.0)$ \\
\hline Physician visits§ & $15.0(5.0-39.0)$ & $8.0(3.0-15.0)$ & $14.0(5.0-38.0)$ & $7.0(3.0-14.0)$ & $14.0(5.0-38.0)$ & $7.0(3.0-14.0)$ \\
\hline No. of physicians§ & $10.0(5.0-18.0)$ & $7.0(3.0-11.0)$ & $10.0(4.0-18.0)$ & $6.0(3.0-11.0)$ & $10.0(4.0-18.0)$ & $6.0(3.0-11.0)$ \\
\hline ED visits & $2.0(0.0-5.0)$ & $0.0(0.0-0.0)$ & $2.0(0.0-5.0)$ & $0.0(0.0-0.0)$ & $2.0(0.0-5.0)$ & $0.0(0.0-0.0)$ \\
\hline \multicolumn{7}{|c|}{$\begin{array}{l}\text { Note: ED = emergency department, IQR = interquartile range. } \\
\text { *Except where indicated otherwise. } \\
\text { †Data for material deprivation were missing for the following numbers of patients: } 1238 \text { of all patients with an overdose-related visit, } 23011 \text { of all patients with a non- } \\
\text { overdose-related visit, } 1100 \text { of patients who were discharged after an overdose-related visit, } 19163 \text { of patients who were discharged after a non-overdose-related visit, } 68 \text { of } \\
\text { patients who left against medical advice after an overdose-related visit and } 1041 \text { of patients who left against medical advice after a non-overdose-related visit. } \\
\text { †For example, zolpidem and zopiclone. } \\
\text { §Community or outpatient. }\end{array}$} \\
\hline
\end{tabular}

emergency department visit among persons with an overdoserelated visit and those with a non-overdose-related visit. For persons who were admitted to a facility after the emergency department visit, the hazard of death was nonproportional over time. Furthermore, these individuals had greater medical complexity, with more severe trajectories, than persons who left the emergency department, either through discharge or against medical advice. Therefore, we excluded admitted patients from the Cox regression analysis.

To explore whether the hazard of death differed between persons with overdose-related and non-overdose-related visits according to disposition among those who left the emergency department, we created a combined, 4-level categorical variable combining disposition status (discharged with approval or left against medical advice) and type of visit (overdose-related or non-overdose-related). We adjusted for age, sex and comorbidity using the Elixhauser index. ${ }^{23} \mathrm{We}$ included these covariables because they are clinically appropriate and reliably coded (least missingness). Our Cox model did not account for censoring due to losses to follow-up: we assumed that persons with no recorded death remained alive, given that 3 years of Client Roster data were needed for a person to be included in our analyses and furthermore that we ascertained death from comprehensive provincial databases.

We performed all analyses with the SAS Enterprise Guide V7.1 (SAS Institute Inc.). 


\section{Ethics approval}

Analysis of the Provincial Overdose Cohort falls under the public health mandate of the BC Centre for Disease Control. Therefore, institutional ethics approval was not required.

\section{Results}

We included 3593 persons with overdose-related and 216453 persons with non-overdose-related visits to the emergency department (Table 1). Relative to those with non-overdoserelated visits, those with overdose-related visits were younger and were more likely to be male, to have mental illness or recent incarceration, and to have longer and higher-acuity emergency department visits (according to the Canadian Triage and Acuity Scale).

\section{Crude mortality}

Crude mortality probabilities are shown in Table 2 and Kaplan-Meier curves by visit disposition in Figure 1. The 12 -month mortality proportion was higher among those with overdose-related visits than among those with nonoverdose-related visits $(5.4 \%, 95 \%$ confidence interval [CI] $4.7 \%-6.2 \%$ v. $1.7 \%$, $95 \%$ CI $1.6 \%-1.8 \%)$. Among persons who left the emergency department (i.e., discharged with approval or left against medical advice), those with overdoserelated visits had higher 12-month mortality than those with non-overdose-related visits. Persons with overdose-related visits who left against medical advice had the most pronounced increase in mortality relative to persons with nonoverdose-related visits $(8.0 \%$, $95 \%$ CI $4.6 \%-13.7 \%$ v. $1.3 \%$, $95 \%$ CI $1.1 \%-1.6 \%)$. There was an unremarkable difference in mortality between persons admitted after overdose and those admitted for non-overdose-related reasons. Figure 2 shows Kaplan-Meier curves according to our 4-level variable combining visit disposition and overdose-related or nonoverdose-related visits.

\section{Hazard ratios}

Adjusted and unadjusted hazard ratios (HRs) from the Cox regression are shown in Table 3. Persons who presented with overdose and were discharged with approval had unadjusted and adjusted mortality HRs of 1.3 (95\% CI 1.0-1.6) and 3.5 (95\% CI 3.0-4.2), respectively, relative to the discharged nonoverdose group. Among persons with overdose who left against medical advice, the unadjusted and adjusted mortality HRs were 5.2 (95\% CI 4.5-6.1) and 7.1 (95\% CI $4.0-12.5)$, respectively, relative to the discharged nonoverdose group.

The adjusted HR for persons with overdose-related visits compared with persons with non-overdose-related visits was higher among those who left against medical advice (HR 5.0, 95\% CI 2.7-9.1) than among those who were discharged (HR 3.5, 95\% CI 3.0-4.2). The adjusted HR for persons who left against medical advice compared with persons who were discharged was higher among those with overdose-related visits (HR 2.0, 95\% CI 1.1-3.6) than among those with non-overdose-related visits (HR 1.4, 95\% CI 1.2-1.7). However, these differences in HR were not statistically significant. Table 2: Crude mortality proportions among persons with
overdose-related and non-overdose-related visits to the
emergency department, overall and by disposition status

\begin{tabular}{|c|c|c|}
\hline \multirow[b]{2}{*}{$\begin{array}{l}\text { Disposition and } \\
\text { time frame, mo }\end{array}$} & \multicolumn{2}{|c|}{$\begin{array}{l}\text { Type of visit; } \\
\% \text { of patients who died }(95 \% \mathrm{Cl})\end{array}$} \\
\hline & $\begin{array}{l}\text { Overdose- } \\
\text { related }\end{array}$ & $\begin{array}{l}\text { Non-overdose- } \\
\text { related }\end{array}$ \\
\hline \multicolumn{3}{|c|}{ Overall (any disposition) } \\
\hline 1 & $0.8(0.6-1.2)$ & $0.4(0.4-0.4)$ \\
\hline 3 & $1.8(1.4-2.3)$ & $0.7(0.7-0.8)$ \\
\hline 6 & $3.5(2.9-4.1)$ & $1.1(1.1-1.1)$ \\
\hline 12 & $5.4(4.7-6.2)$ & $1.7(1.6-1.8)$ \\
\hline \multicolumn{3}{|l|}{ Not admitted* } \\
\hline 1 & $0.7(0.4-1.0)$ & $0.1(0.1-0.1)$ \\
\hline 3 & $1.6(1.3-2.1)$ & $0.3(0.3-0.3)$ \\
\hline 6 & $3.4(2.8-4.0)$ & $0.6(0.5-0.6)$ \\
\hline 12 & $5.3(4.6-6.1)$ & $1.0(1.0-1.1)$ \\
\hline \multicolumn{3}{|c|}{ Discharged to home or place of residence } \\
\hline 1 & $0.6(0.4-1.0)$ & $0.1(0.1-0.1)$ \\
\hline 3 & $1.6(1.2-2.1)$ & $0.3(0.3-0.3)$ \\
\hline 6 & $3.3(2.7-3.9)$ & $0.6(0.5-0.6)$ \\
\hline 12 & $5.1(4.4-6.0)$ & $1.0(1.0-1.1)$ \\
\hline \multicolumn{3}{|c|}{ Left against medical advice } \\
\hline 1 & $2.0(0.7-6.1)$ & $0.2(0.1-0.3)$ \\
\hline 3 & $2.0(0.7-6.1)$ & $0.4(0.3-0.6)$ \\
\hline 6 & $5.3(2.7-10.4)$ & $0.7(0.5-0.9)$ \\
\hline 12 & $8.0(4.6-13.7)$ & $1.3(1.1-1.6)$ \\
\hline \multicolumn{3}{|c|}{ Admitted or transferred } \\
\hline 1 & $2.3(1.1-4.7)$ & $2.9(2.7-3.2)$ \\
\hline 3 & $3.6(2.0-6.3)$ & $4.6(4.3-4.9)$ \\
\hline 6 & $4.8(3.0-7.9)$ & $6.1(5.8-6.4)$ \\
\hline 12 & $6.5(4.2-9.8)$ & $8.2(7.8-8.6)$ \\
\hline
\end{tabular}

Note: $\mathrm{ED}=$ emergency department, $\mathrm{Cl}$ = confidence interval.

*"Not admitted" is a combined category for those who were discharged and those who left against medical advice.

\section{Interpretation}

In this study, we used the Provincial Overdose Cohort to analyze and compare 12-month mortality for persons with overdose-related and non-overdose-related visits to the emergency department in BC. Those with overdose-related visits were younger, were predominantly male and had a higher burden of mental illness. Our analysis showed that 1 in 19 persons presenting to the emergency department after an overdose died in the following year. Importantly, persons who walked out of the emergency department after an overdose-related visit (either discharged with approval or left against medical advice) had at least a 3.5 -fold increased hazard of death in the following year relative to the discharged non-overdose group. 


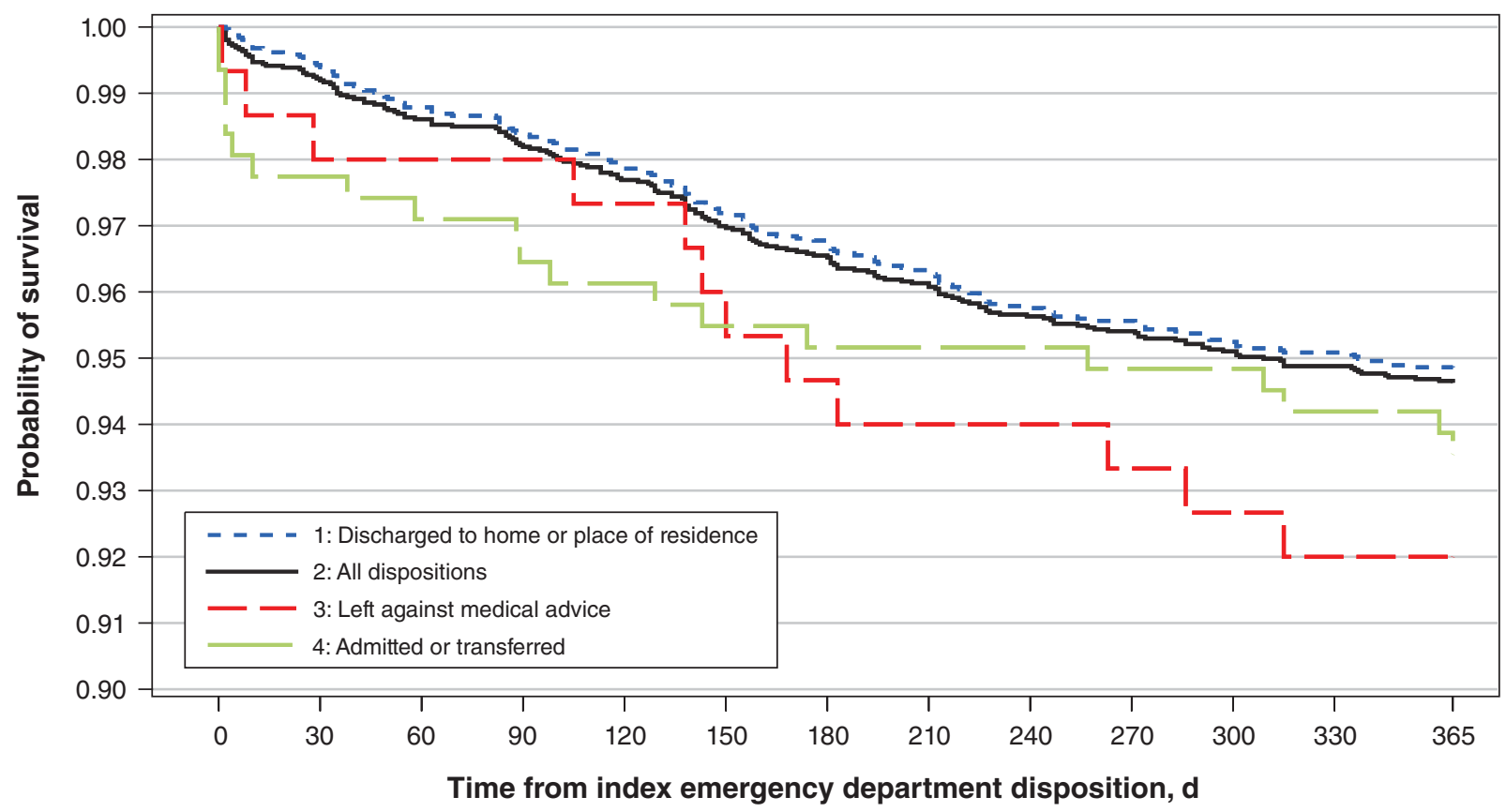

No. of participants at risk

$\begin{array}{rrrrrrrrrrrrrr}1 & 3133 & 3115 & 3095 & 3083 & 3066 & 3045 & 3032 & 3018 & 3000 & 2994 & 2984 & 2979 & 2972 \\ 2 & 3593 & 3565 & 3543 & 3529 & 3510 & 3485 & 3469 & 3454 & 3436 & 3428 & 3417 & 3409 & 3401 \\ 3 & 150 & 147 & 147 & 147 & 146 & 144 & 142 & 141 & 141 & 140 & 139 & 138 & 138 \\ 4 & 310 & 303 & 301 & 299 & 298 & 296 & 295 & 295 & 295 & 294 & 294 & 292 & 291\end{array}$

Figure 1: Kaplan-Meier plot for crude probability of survival, according to disposition, after visits to the emergency department for overdoserelated reasons.

For persons who left against medical advice after an overdoserelated visit, the hazard of death was increased more than sevenfold.

Our finding - that persons who present to the emergency department with overdose are at increased hazard of dying relative to those with non-overdose-related presentations likely reflects several complex underlying medical and socioeconomic factors. Persons presenting to the emergency department with overdose were relatively physically healthy; therefore, intervention may significantly affect qualityadjusted life-years gained.

North American best practice guidelines make various evidence-based recommendations for emergency care of persons with opioid use disorder: targeted screening to identify at-risk persons, symptomatic withdrawal treatment, opioid agonist therapies (buprenorphine-naloxone being the medication of choice), overdose education, take-home naloxone kits and other harm reduction services, and facilitated transition to community addictions care and social stabilization. ${ }^{24-26}$ Strong evidence supports the mortality benefit of opioid agonist treatment; ${ }^{27}$ specifically, buprenorphine-naloxone initiated in the emergency department is safe and cost-effective, and it improves retention in addictions care. ${ }^{11,12,28}$ Furthermore, take-home naloxone kits prevent overdose deaths, and the emergency department is an opportune setting to distribute them. ${ }^{29-31}$

Urgent referral to low-barrier addictions care after an emergency department visit decreases illicit opioid use, and 72-hour follow-up, even if provided at an interim or bridging clinic, is recommended when therapies are initiated from the emergency department. ${ }^{12,32}$ Our results support the need for outpatient referral pathways and clinical interventions to assist persons discharged home after an overdose. Moreover, interventions that integrate addictions specialists in the emergency department team, to facilitate care for patients with opioid use disorder, merit further attention. ${ }^{33,34}$

Furthermore, our results indirectly suggest a need to engage persons who leave against medical advice after their overdose-related visit. Increased probability of dying in this subgroup could be due to underlying health or behaviours (e.g., reluctance to seek medical care). Alternatively, it may indicate that staying for full care in the emergency department can be protective (e.g., receiving counselling, harm reduction services, social work). 


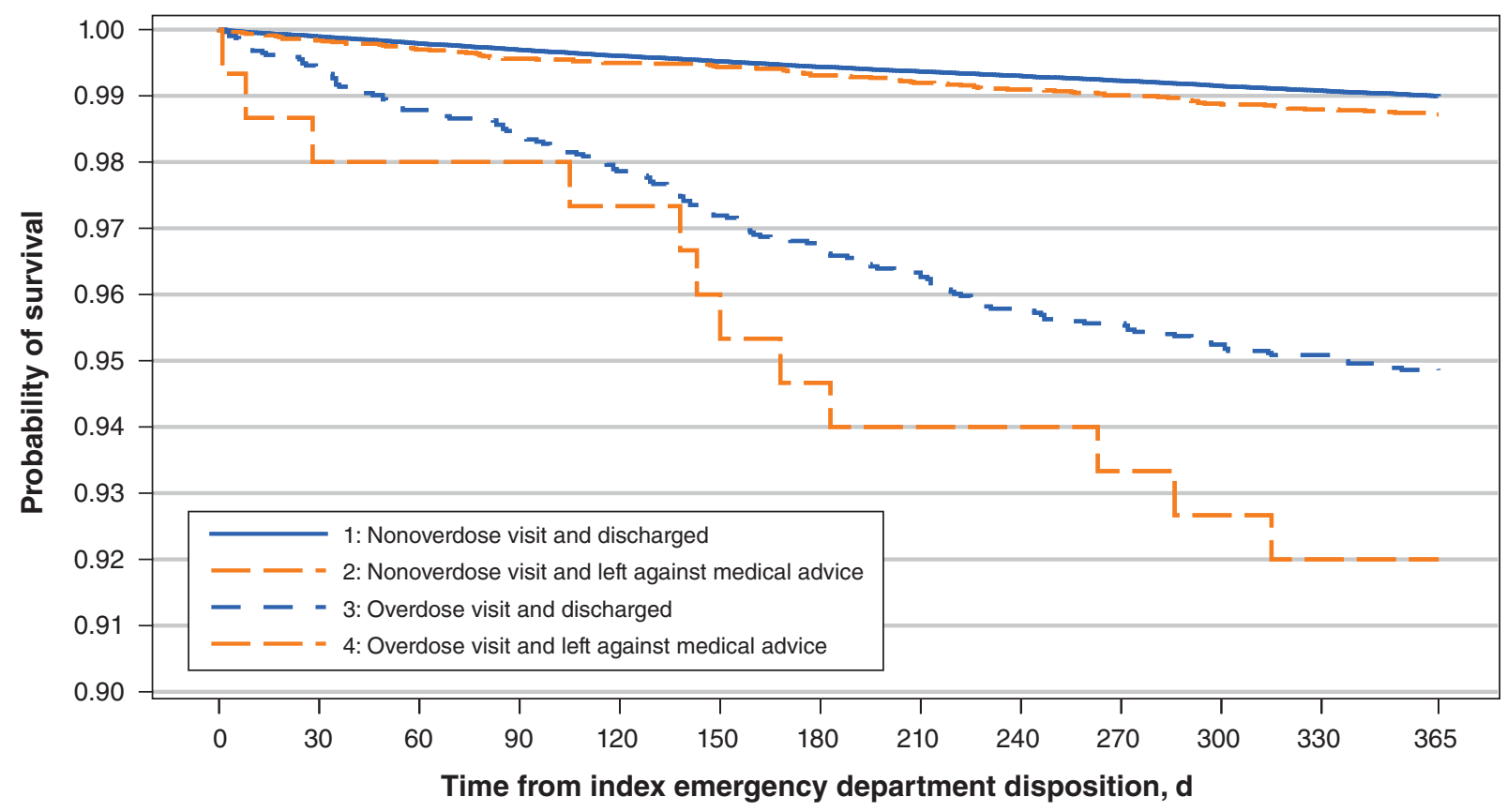

No. of participants at risk

$\begin{array}{rrrrrrrrrrrrrrrr}1 & 187932 & 187737 & 187543 & 187361 & 187188 & 187032 & 186875 & 186746 & 186621 & 186483 & 186332 & 186204 & 186047 \\ 2 & 7960 & 7947 & 7936 & 7925 & 7920 & 7915 & 7905 & 7896 & 7888 & 7881 & 7871 & 7864 & 7858 \\ 3 & 3133 & 3115 & 3095 & 3083 & 3066 & 3045 & 3032 & 3018 & 3000 & 2994 & 2984 & 2979 & 2972 \\ 4 & 150 & 147 & 147 & 147 & 146 & 144 & 142 & 141 & 141 & 140 & 139 & 138 & 138\end{array}$

Figure 2: Kaplan-Meier plot for probability of survival, according to combined variable of disposition and overdose-related or non-overdoserelated visits to the emergency department.

The mortality proportion in our study is comparable to data reported in similar studies of persons seen in the emergency department for overdose from Ontario $(5.3 \%)^{35}$ and Massachusetts (5.5\%). ${ }^{36}$ Given the increasing prevalence of fentanyl in BC's illicit drug supply since $2015^{37-39}$ and evidence of increased probability of fatal overdose when fentanyl analogues are implicated, ${ }^{29}$ mortality after overdose-related visits to the emergency department is now likely higher than during our study period.

Our study confirms previous work indicating that persons who leave against medical advice have poorer outcomes. In a $\mathrm{BC}$ analysis, $9 \%$ of those who left against medical advice after an overdose-related visit to the emergency department experienced a repeat overdose within 1 week. ${ }^{40}$

Multiple previous studies have explored the negative effects of stigma experienced in health care settings by persons who use drugs, including increasing rates of leaving against medical advice. ${ }^{41-44}$ To supplement this evidence, future qualitative studies should explore the experiences of persons receiving post-overdose care in the emergency department and the reasons why people leave against medical advice. Identifying factors (e.g., negative physical triggers, stigmatizing language) that could be modified to make emergency departments more inviting could help inform interventions to prevent persons from leaving against medical advice and to link them with potentially life-saving care (e.g., opioid agonist therapy in the emergency department and linkages to outpatient follow-up, outreach workers or peer supports).

\section{Limitations}

Our study enhances previous literature in that we used a comprehensive, province-wide cohort of linked administrative data to identify and characterize persons with overdoserelated visits to the emergency department. However, the study was limited by the inherent lack of granularity within administrative health databases, which do not include information on specific care received or clinical details that could influence future death, such as vital signs; level of consciousness; need for naloxone, ventilation or other resuscitative interventions; polysubstance use; acute mental health issues; overdose complications such as aspiration or cardiac arrest; or receipt of harm reduction interventions or follow-up care.

Another limitation was our inability to include in our models various socioeconomic variables, such as ethnicity, 
Table 3: Adjusted and unadjusted 12-month mortality hazard ratios for persons with overdose-related versus non-overdoserelated visits to the emergency department who were either discharged with approval or left against medical advice

\begin{tabular}{|c|c|c|}
\hline \multirow[b]{2}{*}{ Model } & \multicolumn{2}{|c|}{ Type of model; hazard ratio $(95 \% \mathrm{Cl})$} \\
\hline & Adjusted* & Unadjusted \\
\hline \multicolumn{3}{|l|}{ Type of visit and disposition } \\
\hline Non-overdose-related and discharged & 1.0 (Ref.) & 1.0 (Ref.) \\
\hline Non-overdose-related and left against medical advice & $1.4(1.2-1.7)$ & $8.3(4.7-14.6)$ \\
\hline Overdose-related and discharged & $3.5(3.0-4.2)$ & $1.3(1.0-1.6)$ \\
\hline Overdose-related and left against medical advice & $7.1(4.0-12.5)$ & $5.2(4.5-6.1)$ \\
\hline \multicolumn{3}{|l|}{ Additional contrasts } \\
\hline $\begin{array}{l}\text { Overdose-related } v \text {. non-overdose-related visits among those who } \\
\text { left against medical advice }\end{array}$ & $5.0(2.7-9.1)$ & $6.5(3.6-11.8)$ \\
\hline $\begin{array}{l}\text { Left against medical advice v. discharged among those with } \\
\text { overdose-related visits }\end{array}$ & $2.0(1.1-3.6)$ & $1.5(0.9-2.9)$ \\
\hline \multicolumn{3}{|l|}{ Age group, yr } \\
\hline $14-35$ & 1.0 (Ref.) & 1.0 (Ref.) \\
\hline $36-55$ & $2.0(1.7-2.3)$ & $2.1(1.8-2.4)$ \\
\hline $56-74$ & $4.5(4.1-5.1)$ & $5.2(4.7-5.9)$ \\
\hline \multicolumn{3}{|l|}{ Sex } \\
\hline Male v. female & $1.7(1.6-1.9)$ & $1.9(1.7-2.1)$ \\
\hline \multicolumn{3}{|l|}{ Elixhauser index with mental health } \\
\hline 0 & 1.0 (Ref.) & 1.0 (Ref.) \\
\hline 1 & $3.8(3.3-4.3)$ & $5.6(4.9-6.5)$ \\
\hline$\geq 2$ & $8.0(7.1-9.0)$ & $10.9(9.4-12.6)$ \\
\hline
\end{tabular}

education, homelessness, individual (rather than neighbourhood) income and employment status, which were unavailable in our linked data. ${ }^{45,46}$ Consistent with existing evidence, we would expect low socioeconomic status, including low income and unstable housing, to increase mortality. ${ }^{45,46}$

Additionally, we applied the Elixhauser index to hospitalization records to examine comorbidity among persons seen in the emergency department. Although this is a validated approach,${ }^{47}$ it may have introduced misclassification bias, because it does not account for persons who did not access health care in the year preceding the emergency visit.

Moreover, our reliance on the NACRS to identify emergency department visits likely biased our sample toward visits that occurred in larger, urban settings, given that 97\% (28/29) of reporting departments in 2014/15 were urban. This may limit the generalizability of our results for smaller, rural departments. Nonetheless, the NACRS remains the most comprehensive database available for emergency visits, with an estimated coverage of $74 \%$ of visits in BC in $2015 / 16$. $^{48}$ Therefore, our provincial-scale analysis offers an important opportunity to understand the crucial issue of death after overdose-related emergency visits.

Our analysis was restricted to overdoses that occurred in $2015 / 16$, because of the delays inherent in any analyses of linked administrative data, where reporting and linkage need to be confirmed. Although we had data available to 2017, we chose 2015/16 as our index year to ensure 1 year of follow-up for all included participants. Nonetheless, given that 2015/16 was the year in which increasing fentanyl prevalence was noted in the illicit drug supply, we expect that our analyses are relevant to the current context in our province. Subsequent evolution of the opioid overdose epidemic in BC, with increasing prevalence of fentanyl, makes it likely that our analysis underestimates the current mortality proportion following overdose-related emergency department visits.

\section{Conclusion}

Persons with overdose-related visits to the emergency department had a higher hazard of 12-month mortality than persons with non-overdose-related visits. Persons who left against medical advice and those discharged with approval were at particularly increased comparative hazard of dying. Our study has important implications for clinical practice. There is an urgent need to better engage persons seen in the emergency department after an overdose and to improve the environment within the emergency department, to prevent them from leaving against medical advice. Such improvements 
would allow clinicians to capitalize on such visits to offer these high-risk patients evidence-based interventions (e.g., naloxone kits, buprenorphine-naloxone or other opioid agonist therapy, referral to follow-up addictions care) that could prevent future death.

\section{References}

1. Measuring the impact of the opioid overdose epidemic on life expectancy at birth in Canada. Ottawa: Government of Canada; 2020. Available: www.canada.ca/ en/health-canada/services/substance-use/problematic-prescription-drug-use/ opioids/data-surveillance-research/measuring-impact-on-life-expectancy.html (accessed 2020 Oct. 28).

2. Changes in life expectancy by selected causes of death, 2017. Ottawa: Statistics Canada; 2019. Available: www150.statcan.gc.ca/n1/daily-quotidien/190530/ dq190530d-eng.htm (accessed 2020 Oct. 28).

3. Ye X, Sutherland J, Henry B, et al. At-a-glance - impact of drug overdoserelated deaths on life expectancy at birth in British Columbia. Health Promot Chronic Dis Prev Can 2018;38:248-51.

4. Provincial health officer declares public health emergency [news release]. Victoria: Government of British Columbia; 2016 Apr. 14. Available: https://news. gov.bc.ca/releases/2016HLTH0026-000568 (accessed 2020 Nov. 25).

5. British Columbia Coroners Service. Illicit drug toxicity deaths in BC, Fanuary 1 , 2020 to October 31, 2020. Victoria: Ministry of Public Safety and Solicitor General; 2020 Nov. 25. Available: www2.gov.bc.ca/assets/gov/birth-adoption -death-marriage-and-divorce/deaths/coroners-service/statistical/illicit-drug.pdf (accessed 2020 Nov 25).

6. Opioid-related harms in Canada, December 2018. Ottawa: Canadian Institute for Health Information; 2018.

7. Moe J, Camargo CA, Jelinski S, et al. Epidemiologic trends in substance and opioid misuse-related emergency department visits in Alberta: a crosssectional time-series analysis. Can $\mathcal{F}$ Public Health 2018;109:164-73.

8. Otterstatter M, Crabtree A, Dobrer S, et al. Analyzing patterns of health care utilization among people who overdose from illegal drugs in British Columbia. Vancouver: British Columbia Centre for Disease Control; 2018.

9. Otterstatter MC, Crabtree A, Dobrer S, et al. Patterns of health care utilization among people who overdosed from illegal drugs: a descriptive analysis using the BC Provincial Overdose Cohort. Health Promot Chronic Dis Prev Can 2018;38:328-33.

10. D'Onofrio G, McCormack RP, Hawk K. Emergency departments - a 24/7/365 option for combating the opioid crisis. NEngl 7 Med 2018;379:2487-90.

11. Kaczorowski J, Bilodeau J, Orkin A, et al. Emergency department-initiated interventions for patients with opioid use disorder: a systematic review. Acad Emerg Med 2020;27:1173-82.

12. D'Onofrio G, O'Connor PG, Pantalon MV, et al. Emergency departmentinitiated buprenorphine/naloxone treatment for opioid dependence: a randomized clinical trial. $7 A M A$ 2015;313:1636-44.

13. Provincial overdose cohort. Vancouver: British Columbia Centre for Disease Control. Available: http://www.bccdc.ca/our-research/projects/overdose -cohort-data (accessed 2020 Oct. 28).

14. MacDougall L, Smolina K, Otterstatter M, et al. Development and characteristics of the Provincial Overdose Cohort in British Columbia, Canada. PLoS One 2019;14:e210129.

15. Slaunwhite A, Otterstatter M, Kuo M, et al. Update to public health stakeholders about a change to the B.C. provincial overdose cohort and overdose surveillance case definition. Vancouver: British Columbia Centre for Disease Control; 2019.

16. Rizi SAM, Roudsari A. Development of a public health reporting data warehouse: lessons learned. Stud Health Technol Inform 2013;192:861-5.

17. National Ambulatory Care Reporting System metadata (NACRS). Ottawa: Canadian Institute for Health Information. Available: www.cihi.ca/en/national-ambulatory -care-reporting-system-metadata-nacrs (accessed 2020 Oct. 28).

18. National Ambulatory Care Reporting System (NACRS) data set. Victoria: PopulationDataBC. Available: www.popdata.bc.ca/data/health/nacrs (accessed 2020 Oct. 28).

19. Data quality documentation, National Ambulatory Care Reporting System: current-year information, 2015-16. Ottawa: Canadian Institute for Health Information; 2016.

20. Smolina K, Crabtree A, Chong M, et al. Prescription-related risk factors for opioid-related overdoses in the era of fentanyl contamination of illicit drug supply: a retrospective case-control study. Subst Abus 2020 May 22;1-7. doi: 10.1080/08897077.2020.1748162. [Epub ahead of print].

21. Smolina K, Crabtree A, Chong M, et al. Patterns and history of prescription drug use among opioid-related drug overdose cases in British Columbia, Canada, 2015-2016. Drug Alcohol Depend 2019;194:151-8.

22. British Columbia Coroners Service. Illicit drug toxicity deaths in BC Fanuary 1 , 2010 to September 30, 2020. Vancouver: British Columbia Centre for Disease Control; 2020.

23. Elixhauser A, Steiner C, Harris DR, et al. Comorbidity measures for use with administrative data. Med Care 1998;36:8-27.

24. Duber HC, Barata IA, Cioè-Peña E, et al. Identification, management, and transition of care for patients with opioid use disorder in the emergency department. Ann Emerg Med 2018;72:420-31.
25. Koh JJ, Klaiman M, Miles I, et al. CAEP position statement: emergency department management of people with opioid use disorder. CFEM 2020;22:768-71.

26. Bruneau J, Ahamad K, Goyer M, et al. Management of opioid use disorders: a national clinical practice guideline. CMA7 2018;190:E247-E57.

27. Sordo L, Barrio G, Bravo MJ, et al. Mortality risk during and after opioid substitution treatment: systematic review and meta-analysis of cohort studies. BM7 2017;357:j1550.

28. Busch SH, Fiellin DA, Chawarski MC, et al. Cost-effectiveness of emergency department-initiated treatment for opioid dependence. Addiction 2017;112:2002-10.

29. Irvine MA, Kuo M, Buxton JA, et al. Modelling the combined impact of interventions in averting deaths during a synthetic-opioid overdose epidemic. Addiction 2019;114:1602-13.

30. Gunn AH, Smothers ZPW, Schramm-Sapyta N, et al. The emergency department as an opportunity for naloxone distribution. West 7 Emerg Med 2018;19:1036-42.

31. McDonald R, Strang J. Are take-home naloxone programmes effective? Systematic review utilizing application of the Bradford Hill criteria. Addiction 2016;111:1177-87.

32. Wiercigroch D, Sheikh H, Hulme J. A rapid access to addiction medicine clinic facilitates treatment of substance use disorder and reduces substance use. Subst Abuse Treat Prev Policy 2020;15:4

33. Mullennix S, Iseler J, Kwiatkowski G, et al. A clinical nurse specialist-led emergency department naloxone distribution program. Clin Nurse Spec 2020;34:116-23.

34. Elphinston RA, Wyder M, De Andrade D, et al. Impact of a new specialist alcohol and drug brief intervention service model integrated into the emergency department: an interrupted time series analysis. Emerg Med Australas 2021;33:67-73.

35. Leece $\mathrm{P}$, Chen $\mathrm{C}$, Manson $\mathrm{H}$, et al. One-year mortality after emergency department visit for nonfatal opioid poisoning: a population-based analysis. Ann Emerg Med 2020;75:20-8.

36. Weiner SG, Baker O, Bernson D, et al. One-year mortality of patients after emergency department treatment for nonfatal opioid overdose. Ann Emerg Med 2020;75:13-17.

37. Opioid overdose emergency in BC. Vancouver: BC Centre for Disease Control. Available: http://www.bccdc.ca/resource-gallery/Documents/Educational \%20Materials/Epid/Other/61718\%20BCCDC\%20Opioid\%20Fact\%20Sheet \%20V3R1\%20\%28F4\%29\%20042418\%20WEB.pdf (accessed 2020 Oct. 28).

38. The BC public health opioid overdose emergency [March 2017 update]. Vancouver: British Columbia Centre for Disease Control; 2017.

39. British Columbia Coroners Service. Fentanyl-detected illicit drug toxicity deaths fanuary 1, 2012 to September 30. Victoria: Ministry of Public Safety and Solicitor General; 2020 Oct. 20.

40. Leaving the emergency department without being seen or against medical advice among people who overdosed from illegal drugs in BC, 2015-2016. Vancouver: British Columbia Centre for Disease Control; 2018.

41. Paquette CE, Syvertsen JL, Pollini RA. Stigma at every turn: health services experiences among people who inject drugs. Int f Drug Policy 2018;57:104-10.

42. McNeil R, Small W, Wood E, et al. Hospitals as a 'risk environment': an ethno-epidemiological study of voluntary and involuntary discharge from hospital against medical advice among people who inject drugs. Soc Sci Med 2014;105:59-66.

43. van Boekel LC, Brouwers EPM, van Weeghel J, et al. Stigma among health professionals towards patients with substance use disorders and its consequences for healthcare delivery: systematic review. Drug Alcohol Depend 2013;131:23-35.

44. Biancarelli DL, Biello KB, Childs E, et al. Strategies used by people who inject drugs to avoid stigma in healthcare settings. Drug Alcobol Depend 2019;198:80-6.

45. Lantz PM, Golberstein E, House JS, et al. Socioeconomic and behavioral risk factors for mortality in a national 19-year prospective study of U.S. adults. Soc Sci Med 2010;70:1558-66.

46. Zivanovic R, Milloy M, Hayashi K, et al. Impact of unstable housing on all-cause mortality among persons who inject drugs. BMC Public Health 2015;15:106.

47. Wei D, Narain A, Lerner J, et al. Validation of comorbidity indices (Charlson and Elixhauser) computed in cross sectional hospital billing data. Value Health 2016 Nov. 16;19:PA477. doi: https://doi.org/10.1016/j.jval.2016.09.755.

48. NACRS emergency department visits and length of stay, 2016-2017. Ottawa: Canadian Institute for Health Information; 2017. Available: www.cihi.ca/en/nacrs -emergency-department-visits-and-length-of-stay-2016-2017 (accessed 2020 Oct. 28).

Affiliations: Department of Emergency Medicine (Moe, Purssell), Vancouver General Hospital; British Columbia Centre for Disease Control (Moe, Chong, Zhao, Slaunwhite); Department of Emergency Medicine (Scheuermeyer), St. Paul's Hospital; British Columbia Drug and Poison Information Centre (Purssell); Department of Emergency Medicine (Moe, Scheuermeyer, Purssell), The University of British Columbia, Vancouver, BC

Contributors: All of the authors conceived of and designed the study. Amanda Slaunwhite acquired the data. Jessica Moe, Mei Chong, 
Bin Zhao and Amanda Slaunwhite analyzed the data, and all of the authors interpreted the data. Jessica Moe drafted the manuscript, and all of the authors revised the manuscript for important intellectual content. All of the authors approved the final version to be published and agreed to be accountable for all aspects of the work.

Funding: None received.

Content licence: This is an Open Access article distributed in accordance with the terms of the Creative Commons Attribution (CC BY-NC-ND 4.0) license, which permits use, distribution and reproduction in any medium, provided that the original publication is properly cited, the use is non-commercial (i.e. research or educational use), and no modifications or adaptations are made. See: https://creativecommons.org/licenses/by-nc-nd/4.0/

Data sharing: Data from the Provincial Overdose Cohort are not publicly available; however, researchers can apply to access this database through Population Data BC (https://www.popdata.bc.ca/).

Supplemental information: For reviewer comments and the original submission of this manuscript, please see www.cmajopen.ca/content/9/1/ E242/suppl/DC1. 